\title{
CORRIGENDUM
}

\section{A Social Benefit-Cost Analysis of Mandatory Deposits on Beverage Containers: A Correction}

\author{
RichaRd C. PORTER \\ Department of Economics, \\ University of Michigan, Ann Arbor, Michigan 48109
}

Received May 10, 1982

In a recent paper in this Journal [1], I conducted a benefit-cost analysis of mandatory deposits under the assumption, made for convenience, that there would be a 100\% switch to refillable beverage containers. In my current work with Michigan's experience [2], I have come to realize that the effects on the container mix are in fact much less dramatic and that the benefit-cost results are very sensitive to this mix. This note shows how the results of the earlier benefit-cost analysis are changed by the assumption that the mix of beverage containers is $50 \%$ refillable bottles and $50 \%$ aluminum cans.

Column 1 of Table I reproduces the findings of the earlier study [1, Table V], with the money figures all raised by $90.6 \%$ to put them into 1981 dollars. ${ }^{1}$ These figures are discussed in the earlier paper; $\bar{x}$ is the mean willingness to pay (in 1981 dollars per year) of Michiganders for an environment that was expected to exhibit about 75\% less beverage-container litter; and $\bar{y}$ is the mean consumer inconvenience cost of returning containers (in 1981 cents per returned container). The locus of values for $\bar{x}$ and $\bar{y}$ that provide net benefits of exactly zero is shown as the dashed line in Fig. $1 .^{2}$

Three estimates need to be corrected to derive this same locus for a 50-50 bottle-can container mix.

1. The greater the use of aluminum cans in the beverage container mix, the smaller the container cost savings. Since the Michigan system already used roughly one fourth refillables before mandatory deposits, a switch to a $50 \%$ refillables system only provides about one third as much saving as a switch to $100 \% .^{3}$ The exact cost saving expected from a 50-50 system (calculated with the estimates of [1, Table IV]) is 2.03 cents per filling ( 1981 prices).

2. That refillable containers cost more than cans to fill and distribute is well known. The additional filling and distribution costs of a mandatory deposit system are therefore smaller with a 50-50 system than a $100 \%$ refillables system. But not much smaller. Empty cans must still be assembled by the retailer and transported to the recycler. Even with $50 \%$ cans, production and distribution cost is raised 4.44 cents per filling.

\footnotetext{
${ }^{1}$ The earlier figures were all for 1974. The CPI rose $90.6 \%$ between 1974 and December 1981.

${ }^{2}$ Taken from [1, Fig. 3], but adjusted to 1981 prices.

${ }^{3}$ That most cans would be recycled provides an indirect container cost reduction; this is considered shortly.
} 
TABLE I

The Social Benefits and Costs Expected from Mandatory Deposits in Michigan in $1981^{\circ}$

Assumption about the container mix

(1)

(2)

\begin{tabular}{|c|c|c|}
\hline Category of benefit $(+)$ or cost $(-)$ & $100 \%$ Refillable bottles ${ }^{b}$ & $50 \%$ Bottles $/ 50 \%$ cans \\
\hline Litter & $+0.29+0.23 \bar{x}$ & $+0.29+0.23 \bar{x}$ \\
\hline Solid waste & +0.13 & +0.13 \\
\hline Containers & +5.87 & $+2.03^{d}$ \\
\hline Production and distribution & -5.28 & $-4.44^{d}$ \\
\hline Consumer inconvenience & $-0.68 \bar{y}$ & $-0.68 \bar{y}$ \\
\hline Recycling value & n.a. ${ }^{c}$ & $+0.79^{d}$ \\
\hline Net & $+1.01+0.23 \bar{x}-0.68 \bar{y}$ & $-1.20+0.23 \bar{x}-0.68 \bar{y}$ \\
\hline
\end{tabular}

${ }^{a}$ All figures are cents per beverage filling sold.

${ }^{b}$ Taken from [1, Table V]; all money figures are raised $90.6 \%$ to reflect 1974-1981 inflation.

${ }^{c}$ n.a. means not applicable.

${ }^{d}$ See text for source of changes from column 1.

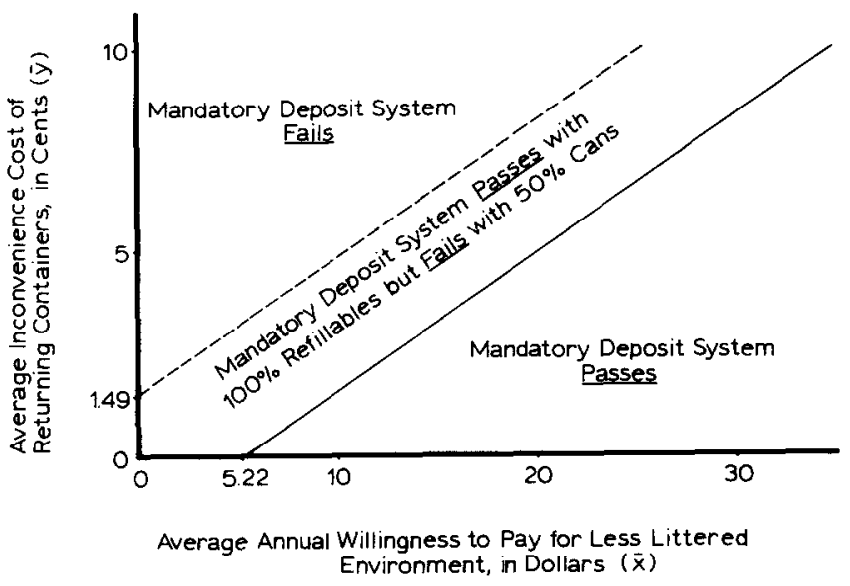

FigURE 1

3. Once one recognizes that cans will remain a significant part of the container mix under mandatory deposits, then one should recognize also that most of these cans will be recollected and yield recycling value to society. The price of a used aluminum can, presumably an acceptable measure of that value, is roughly 1.7 cents (1981 price). On a per-filling basis, this means a benefit of 0.79 cents. $^{4}$

These figures are incorporated into column 2 of Table $I$, and the locus of values of $\bar{x}$ and $\bar{y}$ that yield zero net benefits is shown as the solid line in Fig. 1. In [1], I noted only the dashed line. It is important to notice the solid line for it indicates that there is an important set of values of $\bar{x}$ and $\bar{y}$ for which a mandatory deposit system provides a net social benefit if it induces a complete conversion to refillables but a

${ }^{4} 0.79=(14 / 15)(0.50)(1.7)$, where $14 / 15$ is the can return rate and 0.50 is the assumed percentage of cans in the container mix. 
net social loss if only a partial conversion (50-50) is achieved. Indeed, as Fig. 1 shows, with a 50-50 system and no inconvenience costs on the part of consumers, there must be an annual amenity benefit of at least $\$ 5.22$ per citizen to make mandatory deposits efficient. It is not unreasonable to conclude that the social value of mandatory deposits is quite suspect if they fail to induce a pervasive return to refillable containers. ${ }^{5}$

\section{REFERENCES}

1. R. C. Porter, A social benefit-cost analysis of mandatory deposits on beverage containers, $J$. Environ. Econ. Manag. 5, 351-375

2. R. C. Porter, Michigan's Experience with Mandatory Deposits on Beverage Containers, Land Econ., 59, 177-194.

${ }^{5}$ Why this did not in fact occur in Michigan is discussed elsewhere [2]. 